Entrants will be required to submit an essay describing any recent advance in science (whether their own work or the published work of others) and discussing the potential applications and industrial development of the work; it should be emphasized that the word industrial' is to be read in the broadest sense, including such fields as agriculture, etc. Proof will have to be given that the entrant was actively engaged in scientific research during the period November 1, 1953June 30,1954 . Essays must be submitted by June 30,1954 . Joint entries by not more than two competitors may be submitted. Further details of the competition can be obtained from Research, Butterworths Publications, Ltd., 88 Kingsway, London, IV.C.2.

Since these prize offers were announced, the Sunday Times has offered two further prizes of $£ 100$ and $£ 50$ for the two best entries considered by the Editor, in consultation with the Advisory Board of Research, suitable for publication in a general newspaper and dealing with certain set topics. Further information can be obtained from either Research or the Sunday Times.

\section{B.C.G. Vaccination of School Children}

A CIRCULAR dealing with the vaccination of school children with B.C.G. vaccine has recently been sent to local health authorities by the Ministry of Health. The circular refers to a previous one, and it was after the issue of this latter document that the Minister of Health approved proposals by the local health authorities to enable B.C.C. vaccination to be given to persons known to have been in contact with tuberculous infection. The present circular states that the Minister is now ready to approve the offer of B.C.G. vaccination to school children during and, if possible, towards the end of the year preceding their fourteenth birthday. This extension of the vaccination to school children should not, however, prejudice the scheme for the vaccination of contacts, which should continue. The local health authority will decide, after consultation with the local education authority, whether to extend this vaccination to the school children specified. For their guidance a medical memorandum which has been issued by the Ministry (No. 324 BCG) and discusses the value of B.C.G. vaccination and the techniques to be used by vaccinators, is being sent direct to medical officers of health. The circular states that vaccination should be carried out by designated medical officers on the responsibility of the medical officer of health after consultation with the school medical officer. Most of the vaccinations will be done during the child's penultimate year at school, so that it will be possible to follow up each vaccinated child for at least a year. Children who stay at school after the age of fifteen should also be vaccinated not later than their fourteenth year. The consent of the parents must be obtained before vaccination is done. If the parents are anxious about the vaccinated arm, they may consult the school medical officer or the chest physician, who will consult the family doctor. Talks and discussions are suggested to eliminate fear or misunderstanding of the vaccination. Before the vaccination scheme is extended in the manner just described, local authorities are asked to give the Minister of Health an outline of the way in which they propose to extend the scheme and a statement of the areas to be covered and the measures to be taken for the tracing and vaccination of contacts.

\section{Scottish Marine Biological Association: Millport Laboratory}

ON November 11 the reconstructed public aquarium at the Scottish Marine Biological Association's Millport Laboratory was opened by Dr. J. R. Peddie, secretary and treasurer of the Carnegie Trust for the Universities of Scotland. The original aquarium, constructed in 1904, had served the dual purpose of a public aquarium and tank room for research. It had long been out of date, and three years ago was closed to the public. The Carnegie Trust for the Universities of Scotland had previously made a grant of $£ 600$ a year for five years to cover the construction of a new public aquarium. This has now been achieved, while a separate tank room and aquarium is provided for the use of the scientific workers. The general plan of the public aquarium is the work of Mr. E. Ford, director of the Laboratory, while the internal design of rock is that of Dr. R. B. Pike, principal scientific officer at Millport. A large number of people representing numerous bodies interested in all aspects of the work at Millport attended the opening ceremony, at which the chair was taken by the president, Prof. C. M. Yonge. It is interesting to note that this newest of all public marine aquaria was opened one hundred years after the first such aquarium, due to the enthusiasm of Philip Henry Gosse, was opened, on May 21, 1853, in the Zoo. logical Gardens, London.

\section{The British Trust for Ornithology}

Is addition to twenty-first birthday greetings from many distinguished ornithologists from Great Britain and countries overseas, members of the British Trust for Ornithology should welcome the news from the honorary treasurer that the satisfactory financial position will enable the Trust to extend its inquiries. This is referred to in the report for 1952, which shows that the Trust's membership is continuing to grow. The report contains a valuable statement by Dr. David Lack, director of the Fdward Grey Institute, describing the Trust's part in the launching of the Institute and their present relationship. Work undertaken on behalf of the Trust is also referred to and shows that, in 1952, more heronries were reported than in 1951 and that about 1,500 more nest records were recorded in 1952 than in 1951. The sample census of great crested grebes has been continued, and shows that in 1951 a record total of adult birds was observed. The black redstart inquiry was continued, and confirmed that thirty-one pairs of these birds bred in England in 1951, while seven more pairs were present but not proved to breed. For the first, time on record singing males occupied territories in Scotland. Investigations have also been made into the birds of high-level woodlands, the breeding distribution and habitats of the pied flycatcher, and the wintering of gulls in Britain. Details of the ringing scheme show that more than ten thousand more birds were ringed in 1952 than in 1951. The report also contains an account of the work of the Edward Grey Institute during April 1952-April 1953.

\section{Documentation in Aeronautics Research}

Ax the second meeting in London during September 3-4 of the Documentation Committee of the Advisory Group for Aeronautical Research and Development of the North Atlantic Treaty Organization, it was decided that the activities of the Committee should be given the fullest possible publicity in the aeronautical field. The aims and work of the Documenta. 